\title{
Editorial-1
}

\section{Changing Trends in Research Publication}

Since 10 years, there is an increase in the number of papers, which are getting published; even there is increase in number of journals getting listed in medline. Open access publications have eased the readers. A growth in scientific publishing and the need to publish for academic advancement is a sign of the growth of science. But with this increase in papers, there is greater spread in the quality of these manuscripts, ethics concerns including research integrity, plagiarism and secondary publications.

Plagiarism may arise because of the internal pressure from the department or the university on academic staff to publish. Few times, the authors may not be aware of ethical standards and are not trained, thus do not realize that they should not reproduce the words of others without citing their origin. In other cases they do not take adequate

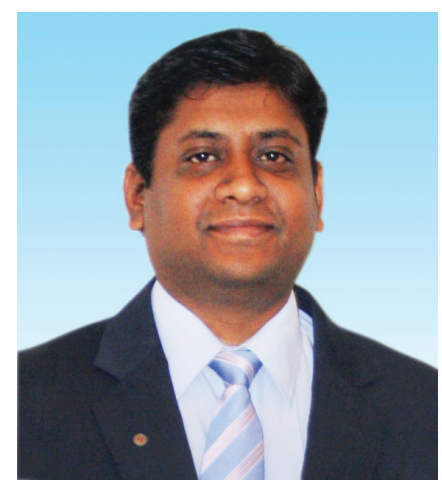
care. I feel that, the responsibility lies with their research leaders, as Deans, Heads of Department or Professors who are expected to set standards and ensure that they are met. There is clearly a large task for those of us who are educators, editors and simple ambassadors of science to make international standards consistent. Automatic screening for plagiarism is already in use by some journals. Continued efforts to ensure that manuscripts follow the journal's guidelines for submission also seem inevitable.

With increase in the manuscripts, the job of specialist reviewing them has also increased. Reviewers generally gain no acknowledgment for reviewing, either in terms of academic recognition or pay. The publishers can collect the charges from the authors for renumarating the reviewers.

Future publications would use more of information technology, with most papers published only in whatever electronic format then exists. Manuscripts might include video sequences to explain the methods used.

There is lot to be discussed by the governing authorities on the changing trends and make research publication more useful to the society and at the same time encouraging the researchers.

\section{BIBLIOGRAPHY}

1. Al Lamki L. Ethics in scientific publication: Plagiarism and other scientific misconduct 2013;28:379-381.

2. Ohno-Machado L. The role of scientific publication in times of changes. J Am Med Inform Assoc 2014;21:1.

Ramesh Chowdhary

Editor-in-Chief 